\title{
La pandemia del coronavirus y su impacto en Asia del Sur
}

\section{Silvana Barrios ${ }^{1}$}

\section{Contribución en la Sección Debates Internacional}

Resumen: Asia del sur cuenta con algunos de los países más poblados del mundo (India, Pakistán y Bangladesh) y desde 2014, ha sido la zona de más rápido crecimiento en el mundo, con un crecimiento anual promedio de $7.0 \%$, siendo ese desempeño impulsado fundamentalmente por India y Bangladesh, con una performance variada en las restantes economías (Song, 2019). En el contexto de la pandemia de coronavirus (COVID-19), iniciada en China, el 1 - de diciembre de 2019, en la ciudad de Wuhan (provincia de Hubei, China) y declarada como pandemia por la Organización Mundial de la Salud, el 11 de marzo de 2020 (OMS, s.f.), este texto busca hacer una breve revisión del alcance de la misma en la región, cuya población es de alrededor de 2000 millones de personas, considerando Afganistán (más de 32 millones de personas), Bangladesh (más de 161 millones de personas), Bután (menos de 800.000 personas), India (más de 1.300 millones de personas), Maldivas (menos de 400.000 personas), Nepal (más de 28 millones de personas), Pakistán (más de 212 millones) y Sri Lanka (más de 21 millones de personas). Para ello, se comentará la cantidad de casos positivos, las muertes en cada país hasta el momento y las principales medidas adoptadas, reflexionando sobre el panorama regional, en base a información de organismos internacionales y noticias periódicas.

\section{Introducción}

Como se conoce, la pandemia de coronavirus (COVID-19), que es causada por el virus coronavirus 2, del síndrome respiratorio agudo grave (SARS-CoV-2), se inició en China (el país más poblado del mundo, con 1.370.536.875 personas, de acuerdo al último censo de 2010) (National Bureau of Statistics of People's Republic of China, 2011), ante la identificación, el 1 · de diciembre de 2019, en la ciudad de Wuhan (provincia de Hubei, China), de un grupo de personas que sufría neumonía de causa desconocida, que estaba relacionada fundamentalmente a trabajadores del mercado mayorista de mariscos, del sur de China.

La Organización Mundial de la Salud la reconoció como una pandemia global, el 11 de marzo de 2020 (OMS, s.f.) y ha alcanzado hasta este momento el diagnóstico de alrededor

\footnotetext{
1 Docente-investigadora; miembro del Grupo de Trabajo sobre India y Asia del Sur, del Comité de Asuntos Asiáticos, del Consejo Argentino para las Relaciones Internacionales/CARI (CABA, República Argentina). Correo electrónico: silvan_barrios@yahoo.com.ar
} 
de 400.000 casos positivos, con más de 17.000 muertos, en más de 160 países, habiéndose transformado en una de las mayores crisis sanitarias de los últimos años (Zafra, Pires, Galocha y Blanco, 2020).

En ese contexto, esta nota se propone revisar brevemente el alcance de la pandemia en Asia del Sur, una de las regiones más pobladas del planeta (The World Bank, 2019), valiéndose para ello de diversas fuentes de información oficial (diversos organismos Internacionales) y noticias periódicas.

\section{Asia del Sur y la situación de la pandemia}

La región de Asia del Sur, reconoce distintos países componentes de la misma, de acuerdo a la consideración de diversas instituciones y/o autores. En esta nota se tomará a Afganistán, Bangladesh, Bután, India, Maldivas, Nepal, Pakistán y Sri Lanka (otros incluyen también a Irán).

Desde el año 2014, esta zona ha sido la de más rápido crecimiento en el mundo, con sus diversas economías, con un crecimiento anual promedio de $7.0 \%$, siendo tal desempeño mayormente impulsado por India y Bangladesh (Song, 2019).

A pesar de su volumen poblacional, alrededor de 2000 millones de personas, los casos de coronavirus permanecen aun siendo pocos, aunque surgen dudas acerca de si ello se debe a la baja cantidad de testeos realizados (Rai,2020).

En el caso del hegemón regional, India, que tuvo su primer caso confirmado el 30 de enero de 2020, sus cifras oficiales hasta el 24 de marzo señalan que el país tiene menos de 500 casos de Covid-19, y 9 personas han fallecido por esta enfermedad (Ward, 2020), sin embargo, tales cifras resultan demasiado benévolas para los expertos -que consideran pueden deberse a los pocos testeos realizados) (Aljazeera, 2020a) y puede que en atención a ello, el Primer Ministro Narendra Modi acabe de decretar un cierre total del país, durante 21 días, desde la medianoche del 25 de marzo (Kulkarni, 2020). Las proyecciones son verdaderamente inciertas, pero es de atender que médicos como el Dr. S.P. Kalantri, superintendente médico del Hospital Kasturba, en el centro de India, temen un horizonte inmediato muy complejo, con la posibilidad de contagio del $55 \%$ de los indios (Ward, 2020).

Pakistán, por su parte, cuenta con 916 casos confirmados al 24 de marzo (más de 400 de ellos en la provincia de Sindh). El país ya prohibió los vuelos internacionales durante dos semanas, a partir del 21 de marzo y en Sindh y en Azad Jammu y Cachemira, administrados por Pakistán, los residentes no pueden salir por ninguna razón innecesaria durante dos y tres semanas respectivamente, al tiempo que el gobierno nacional convocó al ejército para hacer cumplir las restricciones. Paralelamente, el país cerró sus fronteras con 
Irán y Afganistán (Aljazeera, 2020b), mientras los profesionales de la salud reclaman más insumos para trabajar (Fliegauf y Ayres, 2020).

Afganistán, que reportó su primer caso el 24 de febrero, ha dado cuenta de por lo menos 42 casos positivos y 1 muerte, en medio del reclamo del Ministerio de Salud Pública ante el gobierno nacional, para cerrar la provincia de Herat (foco de los casos) y la provisión de más recursos para enfrentar el problema (Fliegauf y Ayres, 2020). Dada su dependencia de sus vecinos en lo que hace a gran parte de sus alimentos, el cierre de sus fronteras con Irán y Pakistán puede señalar el inicio de una crisis mayor (Aljazeera, 2020b).

Por su parte, Bangladesh ha reportado 39 casos positivos y 4 muertes, hasta el momento, aunque los testeos realizados son pocos y las acciones del gobierno nacional han sido lentas (recién a partir del 26 de marzo, se ordenó el cierre de las oficinas durante una semana y se pidió a los ciudadanos permanecer en sus casas, contando con la movilización del ejército para hacer cumplir las medidas) (Fliegauf y Ayres, 2020). Los pasajeros que vienen del exterior y testean positivo deben observar cuarentena obligatoria y todas las instituciones educativas permanecen cerradas hasta el 30 de marzo (Aljazeera, 2020b).

En el caso de Nepal -que reportó su primer caso en enero-, se han producido solamente 2 casos positivos hasta el momento. El 23 de marzo, el país cerró preventivamente las fronteras con China e India para el paso humano, aunque no para las mercancías (PTI, 2020a) y el 24 de marzo comenzó un cierre de una semana en todo el país. El gobierno ha solicitado ayuda para la provisión de distintos insumos a India y China (Kyodo News, 2020).

En una actitud similar a Nepal, Bután, que también cuenta con 2 casos positivos hasta el momento, ordenó también el 23 de marzo el cierre de fronteras con China e India (Lewis, 2020) y determinó que los butaneses que retornen al país sean puestos en cuarentena.

Finalmente, Sri Lanka, que cuenta con 97 casos positivos y ninguna muerte (ColomboPage News Desk, 2020), instituyó el toque de queda para permanecer en los hogares en ocho distritos, desde el 23 al 27 de marzo, incluida la capital, Colombo, habiendo suspendido ya la llegada de vuelos internacionales. Por su parte, Maldivas, que cuenta con 13 casos positivos, ha ido ampliando la lista de países cuyos viajeros no tiene entrada permitida y ha empezado a convertir lujosos resorts en centros para cuarentena de la enfermedad (Markar, 2020), al tiempo que recibe un duro golpe a su exitosa industria de turismo (Aljazeera, 2020b).

\section{A modo de notas finales}

India, en proyección de su rol de liderazgo, ha sido el primero en responder a las necesidades de sus vecinos, con ayudas de distinto tipo y se espera que también lo haga 
China (Chaudhury, 2020). Estados Unidos, por su parte ya se hizo también presente con ayuda para la región (PTI, 2020b).

En el contexto de colaboraciones que se van dando entre los miembros de la Asociación Surasiática para Cooperación Regional (SAARC) y mientras existe temor por los países más poblados, especialmente, frente a sus capacidades sanitarias reales para contener la enfermedad (Slater y Masih, 2020), la región cuenta al mismo tiempo con la ventaja de un gran volumen de población joven (que no aparece como el principal grupo etario de riesgo fatal) y una poderosa industria farmacéutica de genéricos. Resta ver si tales ventajas pueden contrapesar el enorme riesgo que se presenta para la región (y el mundo) y cómo lo que suceda se manifestará en sus desarrollos nacionales futuros y sus proyecciones internacionales.

\section{Referencias}

Aljazeera (18 de marzo de 2020a). India's poor testing rate may have masked coronavirus cases. https://www.aljazeera.com/news/2020/03/india-poor-testing-rate-maskedcoronavirus-cases-

200318040314568.html?utm_source=website\&utm_medium=article_page\&utm_ campaign=read_more_links

Aljazeera (19 de marzo de 2020b). South Asia snapshot: How bad is the coronavirus outbreak? https://www.aljazeera.com/news/2020/03/south-asia-snapshot-badcoronavirus-outbreak-200319113640829.html

ColomboPage News Desk (24 de marzo de 2020). Coronavirus Update: Sri Lanka COVID19 cases count rises to 97 . ColomboPage. http://www.colombopage.com/archive_20A/Mar24_1585031806CH.php

Chaudhury, D. R. (21 de marzo de 2020). India pips China to extend emergency medical supplies to South Asian neighbours. The Economic Times. https://economictimes.indiatimes.com/news/politics-and-nation/india-pips-chinato-extend-emergency-medical-supplies-to-south-asianneighbours/articleshow/74743862.cms?from $=\mathrm{mdr}$

Fliegauf, E. y Ayres, A. (24 de marzo de 2020). Coronavirus in South Asia, March 24, 2020 : Outbreak in Pakistan and India on Lockdown. Council on Foreign Relations. https://www.cfr.org/blog/coronavirus-south-asia-march-24-2020-outbreakpakistan-and-india-lockdown

Kulkarni, S. (24 de marzo de 2020). PM Narendra Modi announces 3-week national lockdown from March 24 midnight. Deccan Herald. 
https://www.deccanherald.com/national/pm-narendra-modi-announces-3-weeknational-lockdown-from-march-24-midnight-817221.html

Kyodo News (24 de marzo de 2020). Nepal locks down for a week to stem coronavirus spread. The Jakarta. https://www.thejakartapost.com/travel/2020/03/24/nepallocks-down-for-a-week-to-stem-coronavirus-spread.html

Lewis, C. (6 de marzo de 2020). Bhutan Closes Borders for Two Weeks After Reporting First Coronavirus Case. Globalbuddhistdoor.

https://www.buddhistdoor.net/news/buddhist-kingdom-of-bhutan-closes-bordersfor-two-weeks-after-reporting-first-coronavirus-case

Markar, M. M. (24 de marzo de 2020). Coronavirus. Maldives converts luxury resorts to coronavirus quarantine centers. Nikkei Asian Review. https://asia.nikkei.com/Spotlight/Coronavirus/Maldives-converts-luxury-resorts-tocoronavirus-quarantine-centers

National Bureau of Statistics of People's Republic of China (2011). Communiqué of the National Bureau of Statistics of People's Republic of China on Major Figures of the 2010 Population Census[1] (No. 1) (April 28). Recuperado de https://web.archive.org/web/20131108022004/http://www.stats.gov.cn/english/ne wsandcomingevents/t20110428_402722244.htm

OMS (s.f.). Brote de enfermedad por coronavirus (COVID-19). Recuperado de https://www.who.int/es/emergencies/diseases/novel-coronavirus-2019

PTI (23 de marzo de 2020a). Nepal seals borders with India, China to prevent Coronavirus outbreak. The Economic Times.

https://economictimes.indiatimes.com/news/politics-and-nation/coronavirusnepal-seals-borders-with-india-china/articleshow/74771722.cms

PTI (19 de marzo de 2020b). US pledges \$ 1.8 million assistance to Nepal to fight coronavirus. Deccan Herald. https://www.deccanherald.com/international/uspledges-18-million-assistance-to-nepal-to-fight-coronavirus-815376.html

Rai, D. (18 de marzo de 2020). Coronavirus in South Asia: Slow spread or not enough tests? India Today. https://www.indiatoday.in/diu/story/coronavirus-in-south-asiaslow-spread-or-not-enough-tests-1656910-2020-03-18

Slater, J. y Masih, N. (19 de marzo de 2020). Home to nearly 2 billion people, South Asia could be the next coronavirus hot spot. The Washington Post. https://www.washingtonpost.com/world/asia_pacific/home-to-nearly-2-billionpeople-south-asia-could-be-the-next-coronavirus-hot-spot/2020/03/19/35431fbe6918-11ea-b199-3a9799c54512_story.html 
Song, L.L. (2 de agosto de 2019). How South Asia can continue as world's fastest growing subregion. Asian Development Bank. https://www.adb.org/news/op-ed/howsouth-asia-can-continue-world-s-fastest-growing-subregion-lei-lei-song

The World Bank (2019). Population density (people per sq. km of land area). Recuperado de https://data.worldbank.org/indicator/EN.POP.DNST

Ward, A. (24 de marzo de 2020). India's coronavirus lockdown and its looming crisis, explained. VoxMedia. https://www.vox.com/2020/3/24/21190868/coronavirusindia-modi-lockdown-kashmir

Zafra, M., Pires, L. S., Galocha, A. y Blanco, P.R. (24 de marzo de 2020). Coronavirus. Casos confirmados en España y en el mundo y claves para entender el coronavirus. El País.

https://elpais.com/sociedad/2020/03/16/actualidad/1584379038_891570.html 